\title{
A Botrytis cinerea Population from a Single Strawberry Field in Germany has a Complex Fungicide Resistance Pattern
}

Anja Grabke, School of Agricultural, Forest \& Environmental Sciences, Clemson University, Clemson, SC 29634; and Gerd Stammler, BASF SE, Agricultural Research Station, 67117 Limburgerhof, Germany

\begin{abstract}
Grabke, A., and Stammler, G. 2015. A Botrytis cinerea population from a single strawberry field in Germany has a complex fungicide resistance pattern. Plant Dis. 99:1078-1086.

Gray mold, caused by the fungus Botrytis cinerea, is one of the most important diseases of strawberry in Germany. The application of sitespecific fungicides remains the main strategy to reduce disease incidence and severity in the field. Isolates $(n=199)$ were collected from fungicidetreated strawberry fruit at a German research site with a long history of fungicide efficacy trials against gray mold. Sensitivities to the six sitespecific botryticides registered in Germany were determined using microtiter assays. Values for the concentration of a fungicide at which fungal development is inhibited by $50 \%\left(\mathrm{EC}_{50}\right)$ ranged from 0.03 to $\geq 30 \mathrm{ppm}$ for the succinate dehydrogenase inhibitor boscalid, 0.015 to $\geq 10 \mathrm{ppm}$ for the hydroxyanilide fenhexamid, 0.009 to $0.739 \mathrm{ppm}$ for the phenylpyrrole fludioxonil, 0.55 to $43.45 \mathrm{ppm}$ for the dicarboximide iprodione, 0.021 to $\geq 3 \mathrm{ppm}$ for the quinone outside inhibitor pyraclostrobin, and 0.106 to $\geq 30 \mathrm{ppm}$ for the anilinopyrimidine pyrimethanil. Pyrosequencing revealed that amino acid substitutions in the target proteins Bos1 (I365S/N, V368F + Q369H), CytB (G143A), Erg27 (F412S),

and SdhB (P225F, N230I, and H272R/Y) were associated with reduced sensitivity levels to the corresponding fungicide classes. In most cases, isolates with a decreased sensitivity to fludioxonil showed a reduced sensitivity to tolnaftate. This reduction is considered to be an indication of multidrug efflux pump activity. The amino acid change I365S, I365N, or V368F + Q369H in Bos1 and $\mathrm{H} 272 \mathrm{R}$ in $\mathrm{SdhB}$ by itself showed $\mathrm{EC}_{50}$ values of 3.99 to $14.73 \mathrm{ppm}, 3.87$ to $5.37 \mathrm{ppm}, 4.81$ to $15.63 \mathrm{ppm}$, and 2.071 to $\geq 30 \mathrm{ppm}$, respectively. When isolates that contained one of these mutations were also multidrug resistant, the ranges of $\mathrm{EC}_{50}$ values shifted to 6.47 to $43.45 \mathrm{ppm}$ for I365S, 7.28 to $29.84 \mathrm{ppm}$ for $\mathrm{I} 365 \mathrm{~N}, 6.89$ to $26.67 \mathrm{ppm}$ for $\mathrm{V} 368 \mathrm{~F}+$ $\mathrm{Q} 369 \mathrm{H}$, and $\geq 30 \mathrm{ppm}$ for $\mathrm{H} 272 \mathrm{R}$. The reported data suggest that the combination of multidrug resistance and an amino acid change in the target site may result in a lower sensitivity to the fungicides than one resistance mechanism by itself. Although $20 \%$ of the population analyzed was sensitive to all six different chemical classes, the majority showed reduced sensitivity to one (6\%), two (13\%), three (23\%), four (17\%), five (11\%), and six (11\%) different fungicides.
\end{abstract}

Strawberry (Fragaria $\times$ ananassa) is one of the most important fruit crops in Germany, ranking only behind grape (Vitis spp.) and apple (Malus domestica Borkh.) in terms of total area harvested (15,004 ha in 2012) and production (155,828 $\mathrm{t}$ in 2012) (FAOSTAT; http://faostat3.fao.org/home/E). The yield of cultivated strawberry is often reduced by abiotic and biotic factors. One of the most economically important diseases that can threaten the strawberry crop is gray mold. The disease is caused by the fungal pathogen Botrytis cinerea Pers., and particularly occurs under moist weather conditions and temperatures around $20^{\circ} \mathrm{C}(7,9,57)$. Conidia serve as the primary source of inoculum. The fungus mainly enters through flowers, in which it usually remains quiescent until the fruit ripens $(5,6,27,28)$. Symptoms eventually appear on green and ripe fruit (50). Secondary infections occur through direct contact of symptomatic plant material with healthy tissue or through conidia spreading via wind or water splashes from infected to healthy fruit (58).

Cultivation practices are applied to reduce gray mold incidence. However, its control in commercial fields remains largely dependent on the application of fungicides. Five classes of site-specific fungicides with different modes of action (MoA) are currently registered for disease management in strawberry in Germany: anilinopyrimidines (APs), hydroxyanilides (HAs), quinone outside inhibitors (QoIs), phenylpyrroles (PPs), and succinate dehydrogenase inhibitors (SDHIs). In various vegetable crops (but currently not in strawberry in Germany), the dicarboximide (DC) iprodione is also

Technical contribution number 6268 of the Clemson University Experiment Station.

Corresponding author: A. Grabke; E-mail: anjag@g.clemson.edu

Accepted for publication 27 January 2015.

http://dx.doi.org/10.1094/PDIS-07-14-0710-RE

(C) 2015 The American Phytopathological Society registered for gray mold control. B. cinerea, however, is known for its high genetic diversity and its potential to readily adapt to chemical control strategies and, in fact, resistance to the different classes of fungicides has previously been reported from strawberry fields in many countries, such as Germany $(33,55)$, Spain (12), and the United States $(13-15,23,24)$.

Fungicide resistance in $B$. cinerea field isolates is commonly caused by amino acid substitutions in the target protein of a fungicide (34). For example, DC resistance has frequently been associated with various amino acid changes in the class III histidine kinase Bos1 of the osmoregulatory pathway $(10,23,40,44)$; high levels of resistance to fenhexamid in $B$. cinerea field isolates are usually due to amino acid substitutions $\mathrm{F} 412 \mathrm{C} / \mathrm{I} / \mathrm{S} / \mathrm{V}$ or $\mathrm{T} 63 \mathrm{I}$ in the 3-ketoreductase Erg27 of the ergosterol biosynthesis pathway $(1,17,24)$; resistance to SDHIs has primarily been associated with amino acid changes $\mathrm{P} 225 \mathrm{~F} / \mathrm{L} / \mathrm{T}, \mathrm{N} 230 \mathrm{I}$, and $\mathrm{H} 272 \mathrm{~L} / \mathrm{R} / \mathrm{Y}$ in subunit $\mathrm{B}$ of the succinate dehydrogenase complex $(\mathrm{SDH})$ in the mitochondrial respiration chain $(35,48)$; and resistance to QoIs is usually caused by amino acid substitution G143A in cytochrome b which blocks the quinol outer (Qo) binding site in the mitochondrial respiration chain (22). Multidrug resistance (MDR), another type of resistance described in B. cinerea field isolates, consists of an increase in fungicide efflux out of cells. This is caused by the overexpression of membrane transport proteins. MDR usually results in simultaneous sensitivity reduction to several unrelated fungicides and is characterized by relatively low resistance factors. Three different types of MDR (MDR1, MDR2, and MDR3) are distinguished in $B$. cinerea isolates. Isolates which have the MDR1 phenotype primarily show reduced sensitivity to APs and PPs, whereas isolates with the MDR2 phenotype are mostly less sensitive to APs, DCs, and HAs. MDR3 is a combination of MDR1 and MDR2 and, thus, results in a hybrid of those two phenotypes $(32,33)$.

Previous research with bacteria and the human pathogenic yeast Candida albicans has shown that the overexpression of membrane transport proteins together with target alterations can provide higher 
levels of resistance to antibiotics than one resistance mechanism by itself $(38,45)$. However, no comprehensive study has been reported in the literature that has analyzed the impact of the combination of two resistance mechanisms on the sensitivities of $B$. cinerea field isolates to the different botryticides. Therefore, the objectives of this study were to (i) assess the current levels of sensitivity of $B$. cinerea isolates obtained from a German research site toward APs, DCs, HAs, PPs, QoIs, and SDHIs; (ii) develop quick and reliable pyrosequencing methods for the detection of associated point mutations in the target genes; (iii) investigate the molecular mechanisms of resistance to the six fungicide classes; and (iv) analyze the impact of the two resistance mechanisms (target site alteration and increased efflux activity) on the sensitivity toward the corresponding fungicides.

\section{Materials and Methods}

Fungal isolates and culture conditions. In total, 199 gray mold samples were obtained from fungicide-treated strawberry fruit, which had been collected at a research site in Limburgerhof, Germany in June 2013. Plots in this field had been treated four times with different spray programs, which contained AP, DC, HA, PP, QoI, and SDHI fungicides, before sampling. Total size of the field was 10 by $25 \mathrm{~m}$, with 420 strawberry plants. Isolation of $B$. cinerea from the field samples was conducted as previously described by Stammler and Speakman (49). Isolates were collected from infected fruit by gently touching sporulating lesions with a sterile cotton swab. Conidia were transferred on $2 \%$ malt extract agar which contained streptomycin at $30 \mathrm{ppm}$. The agar plates were then incubated at room temperature until sporulating colonies of $B$. cinerea had grown. After checking the plates for contamination under the dissecting microscope, a portion of the colony was transferred onto a new $2 \%$ malt extract agar plate. These plates were incubated under light at $20^{\circ} \mathrm{C}(12 \mathrm{~h} /$ day $)$ for 10 to 14 days to promote dense sporulation. B. cinerea strain $\mathrm{B}$, known to be sensitive to all fungicides currently registered for gray mold control, was included in this study as a sensitive standard isolate. Three $B$. cinerea strains previously described by Kretschmer et al. (32) were provided by Matthias Hahn, University of Kaiserslautern, Kaiserslautern, Germany, and used as MDR1 (isolate D06.5-16) and MDR2 reference strains (isolates D06.2-6 and D06.6-5).

Determination of fungicide sensitivities using microtiter assays. The following active ingredients were obtained as formulated compounds and dissolved in sterile deionized water: AP fungicide pyrimethanil (Scala; pyrimethanil at $400 \mathrm{~g} /$ liter; BASF, Ludwigshafen, Germany), DC fungicide iprodione (Rovral Aquaflo; iprodione at $500 \mathrm{~g} /$ liter; BASF), HA fungicide fenhexamid (Teldor; fenhexamid at $500 \mathrm{~g} / \mathrm{kg}$; Bayer Crop Science, Monheim, Germany), QoI fungicide pyraclostrobin (Cabrio; pyraclostrobin at $250 \mathrm{~g} / \mathrm{liter}$; BASF), and SDHI fungicide boscalid (Cantus; boscalid at $500 \mathrm{~g} / \mathrm{kg}$; BASF). The PP fungicides fludioxonil and tolnaftate were used in the form of pure technical active ingredients (Sigma-Aldrich, St. Louis) and were dissolved in dimethyl sulfoxide (DMSO). The final concentration of DMSO was kept below $0.3 \%$ (vol/vol), because control assays had revealed no significant differences in mycelial growth at these concentrations relative to no-solvent controls (data not shown). Spore suspensions were prepared in yeast-Bacto-acetate medium (20 g of yeast extract, $20 \mathrm{~g}$ of Bacto peptone, and $40 \mathrm{~g}$ of sodium acetate in 1 liter of deionized water), except for the pyrimethanil test, in which case glucose gelatin medium $\left(3 \mathrm{~g}\right.$ of $\mathrm{KH}_{2} \mathrm{PO}_{4}, 1.5 \mathrm{~g}$ of $\mathrm{MgSO}_{4} \times 7 \mathrm{H}_{2} \mathrm{O}, 8 \mathrm{~g}$ of gelatin, and $8 \mathrm{~g}$ of glucose in 1 liter of deionized water) was used, and were adjusted to a density of $2 \times 10^{4}$ spores $/ \mathrm{ml}$. All of the fungicide dilutions were prepared in sterile deionized water immediately before mixing with the spore suspension. The following final concentrations were used in the microtiter assays: for fludioxonil and pyraclostrobin, active ingredient at $0,0.003,0.01,0.03,0.1,0.3,1$, and $3 \mathrm{ppm}$; for fenhexamid, active ingredient at $0,0.01,0.03,0.1,0.3,1,3$, and $10 \mathrm{ppm}$; for boscalid, pyrimethanil, and tolnaftate, active ingredient at $0,0.03$, $0.1,0.3,1,3,10$, and $30 \mathrm{ppm}$; and for iprodione, active ingredient at 0 , $0.1,0.3,1,3,10,30$, and $100 \mathrm{ppm}$. The fungicide solutions $(50 \mu \mathrm{l}$ each) were added into 96-well microtiter plates and mixed with $50 \mu \mathrm{l}$ of spore suspension (final concentration $=1,000$ spores/well).
Four replicates were used for each isolate and fungicide concentration. For each of the fungicide concentrations, four replicated wells were used as blanks (fungicide solution + medium). After 5 days of incubation at $18^{\circ} \mathrm{C}$ in darkness, growth was assessed in a photometer at $405 \mathrm{~nm}$, and the values for each fungicide concentration were corrected using the corresponding blanks. Values for the concentration of a fungicide at which fungal development is inhibited by 50 and $90 \%\left(\mathrm{EC}_{50}\right.$ and $\mathrm{EC}_{90}$, respectively) for each isolate were calculated by probit analysis.

Specific detection of point mutations in target genes by pyrosequencing. Several single-nucleotide polymorphisms (SNPs) have previously been found to confer a change in sensitivity to the DC, HA, SDHI, and QoI fungicides of B. cinerea field isolates (11). Pyrosequencing was used in this study to detect the most prevalent of these SNPs in our collection of 199 isolates. Genomic DNA was extracted from pure cultures with the NucleoSpin8/ Plant II kit (Macherey-Nagel, Düren, Germany) following the manufacturer's instructions. The oligonucleotides used in this study were designed with the PSQ Assay Design software (Biotage, Uppsala, Sweden; Table 1). A 183-bp fragment of the gene bosl was amplified with polymerase chain reaction (PCR) primers KES1107 and KES1108 to analyze the codons of amino acid I365, Y368, and Q369 and, if an insertion of alanine is present between amino acid position 370 and 371 of the wild-type protein; a 75-bp (if intron is absent) or a 1,280-bp (if intron is present) fragment of the gene $c y t B$ was amplified with PCR primers KES571 and KES572 to analyze the codon of amino acid G143 and to detect the presence of the intron; a 210-bp fragment of the gene erg27 was amplified with PCR primers KES2002 and KES1909 to analyze the codon of amino acid F412; and a 232-bp fragment of the gene $s d h B$ was amplified with PCR primers KES448 and KES449 to analyze the codons of amino acid P225 and H272. PCR reactions were performed in a final volume of $25 \mu \mathrm{l}$, which contained $50 \mathrm{ng}$ of fungal template DNA, $500 \mathrm{nM}$ of each PCR primer, and $12.5 \mu$ l of $2 \times$ Maxima Hot Start PCR Master Mix (Thermo Fisher Scientific, Waltham, MA). All of the amplification conditions were as follows: $4 \mathrm{~min}$ at $95^{\circ} \mathrm{C}$, followed by 40 cycles of $94^{\circ} \mathrm{C}$ for $15 \mathrm{~s}, 55^{\circ} \mathrm{C}$ for $30 \mathrm{~s}$, and $72^{\circ} \mathrm{C}$ for $15 \mathrm{~s}$, with a final elongation at $72^{\circ} \mathrm{C}$ for $5 \mathrm{~min}$. Every template was duplicated. Streptavidin Sepharose High Performance Beads ( $3 \mu \mathrm{l}$; GE Healthcare Bio-sciences AB, Uppsala, Sweden) and PyroMark binding buffer (37 $\mu$ l; Qiagen, Hilden, Germany) were added to the PCR tubes, which contained the biotinylated PCR products, followed by 15 min of vigorous shaking. The preparation of single-stranded DNA was carried out using the Vacuum Prep Workstation (Biotage), as described by the manufacturer. The single-stranded templates were transferred to $40 \mu \mathrm{l}$ of PyroMark annealing buffer (Qiagen), which contained $300 \mathrm{nM}$ of the corresponding sequencing primer (Table 1), and were incubated at $80^{\circ} \mathrm{C}$ for $2 \mathrm{~min}$. Samples were equilibrated to room temperature and pyrosequenced using PyroMark Gold Q96 reagents (Qiagen) on a PSQ 96 MA Machine (Biotage), as described by the manufacturers.

PCR amplification and sequencing of the genes $\mathrm{erg} 27, \mathrm{sdhB}$, $\boldsymbol{s d h} \boldsymbol{C}$, and $\boldsymbol{s} \boldsymbol{d h} \boldsymbol{h}$. The entire target gene of isolates resistant to a certain fungicide was only sequenced in the absence of SNPs in the corresponding pyrosequencing analysis. The erg27, $s d h B, s d h C$, and $s d h D$ genes were amplified with primer pairs KES2004 + KES2005 (1870 bp), KES429 + KES167 (949 bp), KES622 + KES623 (570 bp), and KES667 + KES668 (656 bp), respectively. PCR reactions were performed in a final volume of $25 \mu 1$, which contained $50 \mathrm{ng}$ of fungal template DNA, $500 \mathrm{nM}$ of each PCR primer, and $12.5 \mu \mathrm{l}$ of $2 \times$ Phusion Flash High-Fidelity PCR Master Mix (Thermo Fisher Scientific). PCR conditions were as follows: $30 \mathrm{~s}$ at $98^{\circ} \mathrm{C}$; followed by 35 cycles of $98^{\circ} \mathrm{C}$ for $10 \mathrm{~s}, \mathrm{X}^{\circ} \mathrm{C}$ for $30 \mathrm{~s}$, and $72^{\circ} \mathrm{C}$ for $\mathrm{Y} \mathrm{s}$, with a final elongation at $72^{\circ} \mathrm{C}$ for $5 \mathrm{~min}$. The annealing temperature $\left(\mathrm{X}^{\circ} \mathrm{C}\right)$ was $58^{\circ} \mathrm{C}$ for $\operatorname{erg} 27,67^{\circ} \mathrm{C}$ for $s d h B, 63.5^{\circ} \mathrm{C}$ for $s d h C$, and $66^{\circ} \mathrm{C}$ for $s d h D$. The elongation time (Y s) was $30 \mathrm{~s}$ for $\operatorname{erg} 27,20 \mathrm{~s}$ for $s d h B, 15 \mathrm{~s}$ for $s d h C$, and $12.5 \mathrm{~s}$ for $s d h D$. PCR products were separated by gel electrophoresis and extracted with the NucleoSpin Gel and PCR Clean-up kit (Macherey-Nagel). The erg27 gene was sequenced with primers KES2004, KES2005, erg27_Beg, and erg2000_up, whereas $s d h B, s d h C$, and $s d h D$ were first cloned in XL-1 Blue Competent Cells (Agilent Technologies) using the 
CloneJET PCR Cloning Kit (Fermentas GmbH, St. Leon-Rot, Germany) following the manufacturer's instructions. Plasmid DNA was extracted with the NucleoSpin Plasmid kit (Macherey-Nagel) and Sanger sequenced using primers pJet $1.2 \mathrm{fw}$ (5'-CGACTCACTATA GGGAGAGCGGC-3') and pJet1.2 rv (5'-AAGAACATCGATTTTC CATGGCAG-3')

Spore germination assay. Two isolates (64208 and 64209) showed high levels of HA resistance in the microtiter assay $\left(\mathrm{EC}_{50}\right.$ value $\left.\geq 10\right)$ but did not have any amino acid change in Erg27. To assess whether these two isolates were metabolizing fenhexamid, a conidia germination assay previously published by Weber and Hahn was conducted using discriminatory doses of formulated fenhexamid at 1 and $50 \mathrm{ppm}$ on $1 \%$ malt extract agar and formulated fenhexamid at $10 \mathrm{ppm}$ on $1.5 \%$ water agar (56). Isolates B and 64266 (with amino acid change F412S) were added as sensitive and resistant controls, respectively. A $50-\mu l$ droplet of spore suspension ( 1 to $5 \times 10^{5}$ spores $/ \mathrm{ml}$ ) was streaked out across the agar plates for each isolate and each fungicide concentration. The plates were then incubated at $20^{\circ} \mathrm{C}$ in the dark and germ tube growth was visually assessed with a compound microscope after 14, 24, and $36 \mathrm{~h}$ of incubation. The experiment was replicated once.

\section{Results}

Sensitivity of $B$. cinerea to AP, DC, HA, PP, QoI, and SDHI fungicides. In the microtiter assays, the sensitivities of $B$. cinerea field isolates toward AP, DC, HA, PP, QoI, and SDHI fungicides covered broad ranges (Fig. 1). The $\mathrm{EC}_{50}$ values for the $\mathrm{SDHI}$ fungicide boscalid ranged from 0.03 to $\geq 30 \mathrm{ppm}$, with a median of $5.214 \mathrm{ppm}$ (Fig. 1A). The majority of the field isolates and the sensitive reference strain had $\mathrm{EC}_{50}$ values below $0.5 \mathrm{ppm}$ and, thus, were considered sensitive. Although many isolates had an $\mathrm{EC}_{50}$ value above $25 \mathrm{ppm}$, the $\mathrm{EC}_{50}$ values of some isolates were scattered between 1.5 and $15 \mathrm{ppm}$. For fenhexamid, the $\mathrm{EC}_{50}$ values covered a range from 0.015 to $\geq 10 \mathrm{ppm}$, with a median of $0.048 \mathrm{ppm}$ (Fig. 1B). In all, $77 \%$ of the field isolates as well as the sensitive reference strain had an $\mathrm{EC}_{50}$ value below $0.3 \mathrm{ppm}$. One isolate had an $\mathrm{EC}_{50}$ value of $1.58 \mathrm{ppm}$, and the remaining isolates were above $3 \mathrm{ppm}$. For fludioxonil, the $\mathrm{EC}_{50}$ values increased almost continuously and ranged from 0.009 to $0.739 \mathrm{ppm}$, with a median of $0.035 \mathrm{ppm}$ (Fig. 1C). For iprodione, $\mathrm{EC}_{50}$ values ranged from 0.55 to
$43.45 \mathrm{ppm}$, with a median of $1.55 \mathrm{ppm}$ (Fig. 1D). The isolates could be separated into two main groups: one consisted of isolates with $\mathrm{EC}_{50}$ values above $3.6 \mathrm{ppm}$ and the other with $\mathrm{EC}_{50}$ values below $1.85 \mathrm{ppm}$. For pyraclostrobin, most of the isolates $(69 \%)$ had an $\mathrm{EC}_{50}$ value $\geq 3 \mathrm{ppm}$. The remaining isolates and the sensitive reference strain had $\mathrm{EC}_{50}$ values between $0.021 \mathrm{ppm}$ and $0.206 \mathrm{ppm}$ and, thus, were considered sensitive (Fig. 1E). The $\mathrm{EC}_{50}$ values for pyrimethanil increased almost continuously and ranged from $0.106 \mathrm{ppm}$ and $\geq 30 \mathrm{ppm}$, with a median of $17.28 \mathrm{ppm}$ (Fig. 1F).

Sensitivity of $B$. cinerea to fludioxonil, pyrimethanil, and tolnaftate as indication for MDR. When analyzing the $\mathrm{EC}_{90}$ values of fludioxonil, we observed that the $B$. cinerea isolates analyzed could easily be separated into two main groups: one with $\mathrm{EC}_{90}$ values below $0.09 \mathrm{ppm}$ and one above $0.235 \mathrm{ppm}$ (Fig. 2A). The isolates with increased $\mathrm{EC}_{90}$ values for fludioxonil almost always had a higher $\mathrm{EC}_{90}$ value for tolnaftate compared with the MDR1 and MDR2 reference strains (except for three isolates) (Fig. 2B) and, thus, were considered to be MDR. Interestingly, these isolates showed increased $\mathrm{EC}_{50}$ values for the AP fungicide pyrimethanil (Fig. 3E), which suggests that they may be MDR1.

Different resistance mechanisms and their impact on fungicide sensitivities. Amino acid substitutions in the target proteins Bos1, CytB, Erg27, SdhB, SdhC, and SdhD and MDR have previously been associated with changes in sensitivity levels to fungicides and, thus, were analyzed in this study. Isolates with the highest sensitivity values to the different fungicides were always isolates without target gene alterations. Low $\mathrm{EC}_{90}$ values for fludioxonil and tolnaftate indicate that these isolates were not MDR (Fig. 3). Thus, they were considered to be sensitive. With the exception of pyraclostrobin, isolates without point mutation in the target gene that were also considered to be MDR usually showed a shifted range of $\mathrm{EC}_{50}$ values to lower sensitivities when compared with isolates that were probably not MDR and contained no point mutations.

Boscalid. Four different amino acid changes were found in SdhB of isolates with reduced sensitivities to boscalid (Fig. 3A). Each of these mutations seemed to have a different impact on the sensitivity to this fungicide. Nine of the $B$. cinerea isolates in this study had an amino acid substitution from proline to phenylalanine at position $225(\mathrm{P} 225 \mathrm{~F})$, which was always associated with an $\mathrm{EC}_{50}$

Table 1. Name, sequence, direction, and application of oligonucleotides used in this study for the detection of point mutations in target genes

\begin{tabular}{|c|c|c|c|c|}
\hline Gene & Primer & Sequence $\left(5^{\prime}-3^{\prime}\right)$ & Strand $^{\mathbf{a}}$ & Application $^{\mathbf{b}}$ \\
\hline \multirow[t]{3}{*}{$\overline{b o s} 1$} & KES 1107 & AGCCCAGGGTGAGATACTCCAAC & fw & Pyroseq.: PCR (detection of I365 N/R/S, V368F, Q369H/P, Ins371) \\
\hline & KES 1108 & Biotin-CGTTGACGTTCACTATCAATGTGT & rv & Pyroseq.: PCR (detection of I365 N/R/S, V368F, Q369H/P, Ins371) \\
\hline & KES 1993 & GGGGTCAAGCAGAA & fw & Pyroseq.: Seq. (detection of I365 N/R/S, V368F, Q369H/P, Ins371) \\
\hline \multirow[t]{3}{*}{$c y t B$} & KES 571 & TACGGGCAAATGTCACTGTG & fw & Pyroseq.: PCR (detection of G143A, intron) \\
\hline & KES 572 & Biotin-TCTTGTCCAATTCATGGTACAGC & rv & Pyroseq.: PCR (detection of G143A, intron) \\
\hline & KES 573 & GGGCAAATGTCACTGT & fw & Pyroseq.: Seq. (detection of G143A, intron) \\
\hline \multirow[t]{7}{*}{$\operatorname{erg} 27$} & KES 2002 & GAGGAAGAGCCAGCAGCAAAA & fw & Pyroseq.: PCR (detection of F412C/I/S/V) \\
\hline & KES 1909 & Biotin-TCGGGAGATAATGCTACCCAGA & rv & Pyroseq.: PCR (detection of F412C/I/S/V) \\
\hline & KES 2001 & TGGTATTTATCTACAGATTG & fw & Pyroseq.: Seq. (detection of F412C/I/S/V) \\
\hline & KES 2004 & TGCTCCCTATAGTTTCAACC & fw & Seq. of entire gene: PCR and Seq. \\
\hline & KES 2005 & AGCAAAAGAGTTTGAACAGG & rv & Seq. of entire gene: PCR and Seq. \\
\hline & erg27_Begc & TGGGATTACCACCATGGGAGACAAGTG & fw & Seq. of entire gene: internal Seq. primer \\
\hline & erg2000up ${ }^{c}$ & TCGGAGGGTTTGGCTTGTTTTG & rv & Seq. of entire gene: internal Seq. primer \\
\hline \multirow[t]{6}{*}{$\operatorname{sdh} B$} & KES 448 & ATTCTCTGCGCATGCTGCTC & fw & Pyroseq.: PCR (detection of $\mathrm{H} 272 \mathrm{R} / \mathrm{Y}, \mathrm{P} 225 \mathrm{~F} / \mathrm{L} / \mathrm{T}$ ) \\
\hline & KES 449 & Biotin-CAATTGCCAAACCAGGATTCA & rv & Pyroseq.: PCR (detection of H272R/Y, P225F/L/T) \\
\hline & KES 451 & GCATGAGTTTGTACAGATGT & fw & Pyroseq.: Seq. (detection of H272R/Y) \\
\hline & KES 460 & TGCTCGACATCTTGC & fw & Pyroseq.: Seq. (detection of P225F/L/T) \\
\hline & KES 429 & ATGGCTGCTCTCCGCACAG & fw & Seq. of entire gene: PCR \\
\hline & KES 167 & TGCTATCTCATCAAGCCCCCT & rv & Seq. of entire gene: PCR \\
\hline \multirow[t]{2}{*}{$s d h C$} & KES 622 & ATGTTTTCACAGAGAGCAACTCAAC & fw & Seq. of entire gene: PCR \\
\hline & KES 623 & CTACAAGAAAGCAACCAACGC & rv & Seq. of entire gene: PCR \\
\hline \multirow[t]{2}{*}{$s d h D$} & KES 667 & ATGGCTTCATTCATCAAACCATC & fw & Seq. of entire gene: PCR \\
\hline & KES 668 & TTATGCGCGCCAAATTCTTTTG & rv & Seq. of entire gene: PCR \\
\hline
\end{tabular}

a DNA strand direction: $\mathrm{fw}=$ forward and $\mathrm{rv}=$ reverse.

b Pyroseq = pyrosequencing, PCR = polymerase chain reaction, Seq = sequencing, and Ins $371=$ insertion of the amino acid alanine between amino acid position 371 and 372.

c Primers were previously described (17). 
value $\geq 30 \mathrm{ppm}$. The amino acid change from asparagine to isoleucine at position $230(\mathrm{~N} 230 \mathrm{I})$ was observed in two isolates with $\mathrm{EC}_{50}$ values of 1.593 and $2.941 \mathrm{ppm}$, which indicates that this amino acid change causes a low to moderate decrease in the sensitivity to boscalid. Most of the isolates $(n=93)$ had a mutation at codon 272, which resulted in an amino acid change from histidine to either arginine (H272R, $n=80$ ) or tyrosine (H272Y, $n=13$ ). Isolates with the amino acid substitution H272R showed a broad range of sensitivities, from 2.071 to $\geq 30 \mathrm{ppm}$. Interestingly, all isolates $(n=34)$ with the $\mathrm{H} 272 \mathrm{R}$ mutation that were considered to be MDR had an $\mathrm{EC}_{50}$ value $\geq 30 \mathrm{ppm}$, which suggests that the H272R mutation, in combination with MDR, may result in a lower sensitivity to boscalid than one resistance mechanism by itself. The 34 isolates with the combination of H272R and MDR also had various sensitivity levels to the other fungicides tested and different target gene alterations, which excluded the possibility that they were clones. The 13 isolates with amino acid change H272Y revealed low levels of sensitivity $\left(\mathrm{EC}_{50}\right.$ value $\left.\geq 30 \mathrm{ppm}\right)$. Four isolates with $\mathrm{EC}_{50}$ values $\geq 30 \mathrm{ppm}$ contained uncommon nucleotide changes leading to amino acid variations (data not shown). A combination of amino acid changes (A85G, V93I, V158M, and I168V) in SdhC was present in three isolates. The same isolates also contained the N230I mutation associated with a low to moderate decrease in sensitivity to boscalid (Fig. 3); thus, it is unclear whether the mutations in SdhC are contributing to the resistant phenotype. The same was the case for an isolate with amino acid changes $\mathrm{N} 230 \mathrm{I}$ in $\mathrm{SdhB}$ and $\mathrm{P} 67 \mathrm{~T}$ in $\mathrm{SdhD}$, which also had an $\mathrm{EC}_{50}$ value $\geq 30 \mathrm{ppm}$.

Fenhexamid. $\mathrm{EC}_{50}$ values above $3 \mathrm{ppm}$ were almost exclusively linked to amino acid substitution F412S, with the exception of two isolates (Fig. 3B). The absence of mutations in the entire erg27 gene of these two isolates shows that no target gene mutation was responsible for their low sensitivity levels. Their germ tube growth on water agar amended with fenhexamid at $10 \mathrm{ppm}$ indicated that their resistance was not based on a metabolization of fenhexamid in the presence of sugars. A combination of two mutations in erg27 was present in the single isolate with an $\mathrm{EC}_{50}$ value of $1.58 \mathrm{ppm}$, resulting in the replacement of valine with isoleucine at amino acid position 234 (V234I) and isoleucine to valine at amino acid position 235 (I235V). Because these mutations were found only in this isolate, it is unclear as to whether V234I and I235V contributed to the decrease in fenhexamid sensitivity.

Iprodione. Three different genotypes were obtained for isolates with reduced sensitivities to iprodione, each of them with similar
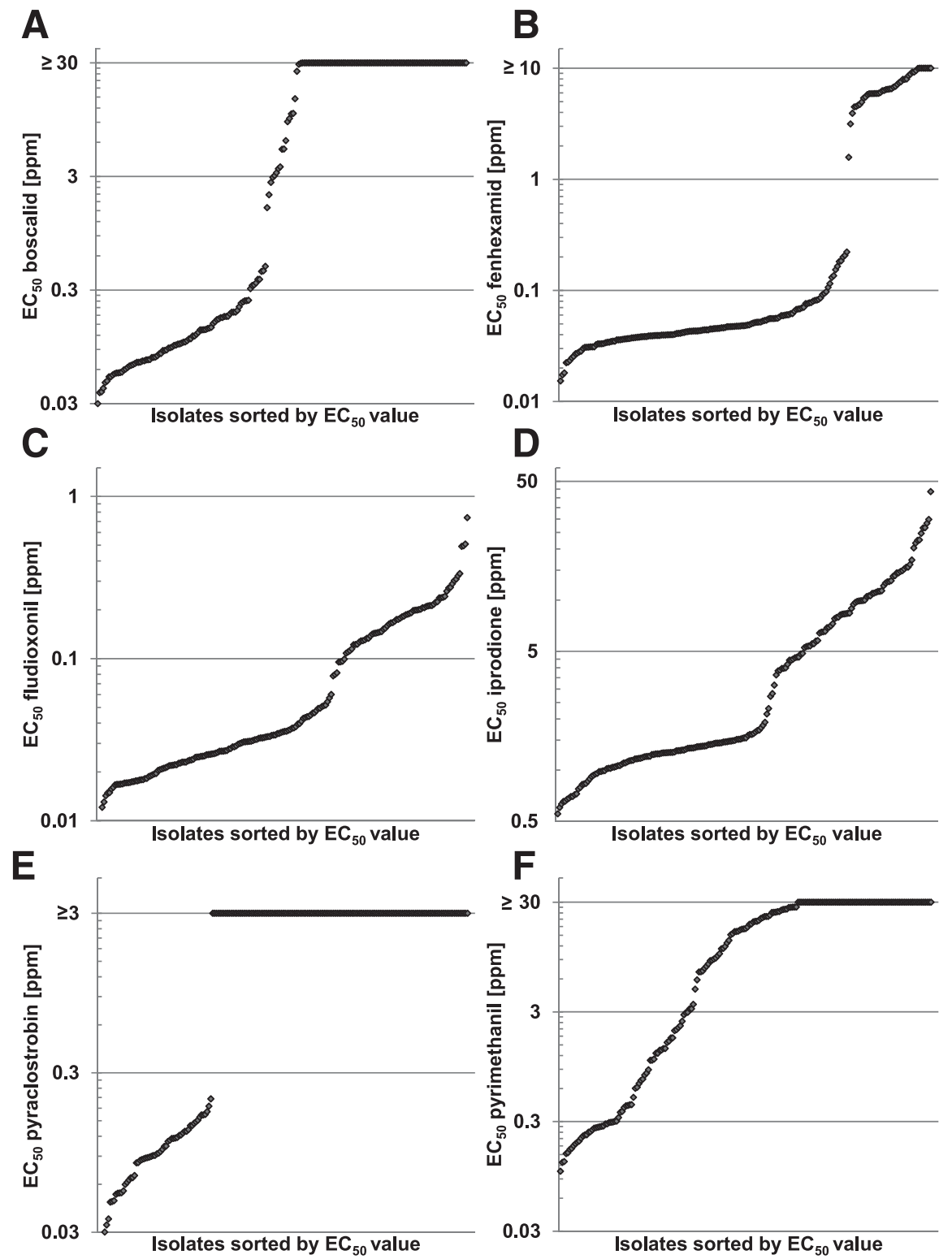

Fig. 1. Sensitivities of Botrytis cinerea isolates toward different fungicides. Isolates are sorted by rising values for the concentration of a fungicide at which fungal development is inhibited by $50 \%$ ( $\mathrm{EC}_{50}$ ) of $\mathbf{A}$, boscalid; $\mathbf{B}$, fenhexamid; $\mathbf{C}$, fludioxonil; $\mathbf{D}$, iprodione; $\mathbf{E}$, pyraclostrobin; and $\mathbf{F}$, pyrimethanil. 
ranges of $\mathrm{EC}_{50}$ values (Fig. $3 \mathrm{C}$ ). In all, 46 isolates had a mutation at codon 365 , resulting in an amino acid change from isoleucine to either serine (I365S, $n=26$ ) or asparagine (I365N, $n=20)$. A combination of two point mutations in bos 1 was present in the remaining 33 isolates, resulting in the replacements of valine with phenylalanine at amino acid position 368 (V368F) and glutamine with histidine at amino acid position 369 (Q369H). Sequence analysis of a bos 1 fragment of four isolates with $\mathrm{V} 368 \mathrm{~F}$ and Q369H revealed the presence of a third amino acid change from threonine to serine at amino acid position 447 (T447S). These four isolates were picked from the low and high ends of the sensitivity scale, which suggests that T447S was either present in all isolates with the $\mathrm{V} 368 \mathrm{~F}$ and $\mathrm{Q} 369 \mathrm{H}$ mutations or does not affect the sensitivity to iprodione. Interestingly, when comparing isolates considered to be MDR with isolates which are probably not $\mathrm{MDR}$, the range of $\mathrm{EC}_{50}$ values of MDR isolates was at lower sensitivity levels compared with non-MDR isolates. This shift was found for each of the four categories (no mutation, I365S, I365N, and $\mathrm{V} 368 \mathrm{~F}+\mathrm{Q} 369 \mathrm{H})$. In the case of isolates with the $\mathrm{I} 365 \mathrm{~N}$ mutation, the median of the $\mathrm{EC}_{50}$ values was $4.29 \mathrm{ppm}$ for non-MDR and $13.4 \mathrm{ppm}$ for MDR isolates; for isolates with the I365S mutation, the median was $6.51 \mathrm{ppm}$ for non-MDR and $21.66 \mathrm{ppm}$ for MDR; and for isolates with the $\mathrm{V} 368 \mathrm{~F}+\mathrm{Q} 369 \mathrm{H}$ mutation, the median was $7.48 \mathrm{ppm}$ for nonMDR and 11.24 for MDR. These results suggest that the combination of MDR and amino acid changes in the target site may result in a lower sensitivity to iprodione than one resistance mechanism by itself.

Pyraclostrobin. Two genotypes of sensitive isolates with similar $\mathrm{EC}_{50}$ values were observed for pyraclostrobin (Fig. 3D). Both types had a glycine at amino acid position 143 (G143) but were different due to the absence or presence of an intron after G143. All 138 isolates with $\mathrm{EC}_{50}$ values $\geq 3 \mathrm{ppm}$ had the well known substitution of glycine to alanine at amino acid position 143 (G143A).

Pyrimethanil. Isolates that were considered to be MDR generally had decreased $\mathrm{EC}_{50}$ values, which suggests that this type of MDR reduces the sensitivity to AP fungicides (Fig. 3E). In all, 23\% of the isolates which were not $\mathrm{MDR}$ also had $\mathrm{EC}_{50}$ values $\geq 30 \mathrm{ppm}$, a possible indication that the reduction of sensitivity is not solely based on MDR.

Reduced sensitivities to multiple fungicides in individual isolates. In order to evaluate how many individual isolates had accumulated reduced sensitivities to multiple fungicides, we grouped our collection of isolates into two main categories for each fungicide class. Isolates with $\mathrm{EC}_{50}$ values above 1.5, 1.5, 0.075, 3.8, 3, and $6.9 \mathrm{ppm}$ for boscalid, fenhexamid, fludioxonil, iprodione, pyraclostrobin, and pyrimethanil, respectively, were grouped as reduced sensitive for the relevant fungicide, while isolates with lower $\mathrm{EC}_{50}$ values were considered to be sensitive. This distinction was based on gaps in the sensitivity graphs illustrated in Figure 1. The results are shown in Figure 4. In total, $20 \%$ of the $B$. cinerea population analyzed was sensitive to all six different chemical classes. However, the majority of isolates showed reduced sensitivity to one or more fungicides: $6,13,23,17,11$, and $11 \%$ of isolates had decreased sensitivity values to one, two, three, four, five, and six chemical classes, respectively. Isolates with reduced sensitivity to six botryticides were always MDR and contained target gene mutations. These results illustrate the high levels of reduced sensitivities to multiple fungicide classes in the German strawberry field.

\section{Discussion}

This study documents that broad ranges of fungicide sensitivities are present in $B$. cinerea field isolates from a research site in Germany. For the development of resistance management strategies, it is important to know that sensitive isolates to all of the different fungicide classes are still present in the field. It is also critical that a large proportion of the $B$. cinerea population shows highly reduced sensitivity levels.

At least 24 genotypes with different combinations of point mutations in $c y t b$, bos 1, erg27, and $s d h B$ were obtained in this study (data not shown). These genotypes also showed various levels of fludioxonil and pyrimethanil resistance, which indicated that the $B$. cinerea isolates collected from strawberry fruit were highly heterogeneous. This observation is in line with findings in other scientific studies. For example, $B$. cinerea isolates from grape and kiwi fruit contained large amounts of intrapopulation genetic variation $(3,21)$, B. cinerea populations from vegetables in glasshouses in Spain were highly heterogeneous (2), and $B$. cinerea samples collected inside and outside a glasshouse were almost all genetically different (31). Considering the fact that all 199 isolates in our study were collected from a very small strawberry field on the same day, the high diversity appears especially remarkable, and this diversity could be an explanation for the fast adaptability of $B$. cinerea toward fungicides.

Reduced fungicide sensitivities in our $B$. cinerea population were associated with two mechanisms of resistance. Low sensitivity levels to boscalid, fenhexamid, iprodione, and pyraclostrobin were usually linked with amino acid changes in the target proteins $\mathrm{SdhB}$, Erg27, Bos1, and CytB, respectively. These substitutions have previously been described in $B$. cinerea field isolates in many studies, indicating that they were most likely causing the sensitivity shift $(1,10,17,22-24,35,40,44,48)$.

When analyzing fludioxonil sensitivities, our collection of $B$. cinerea isolates separated into two main groups. The isolates with reduced sensitivities to fludioxonil (except for three isolates) also
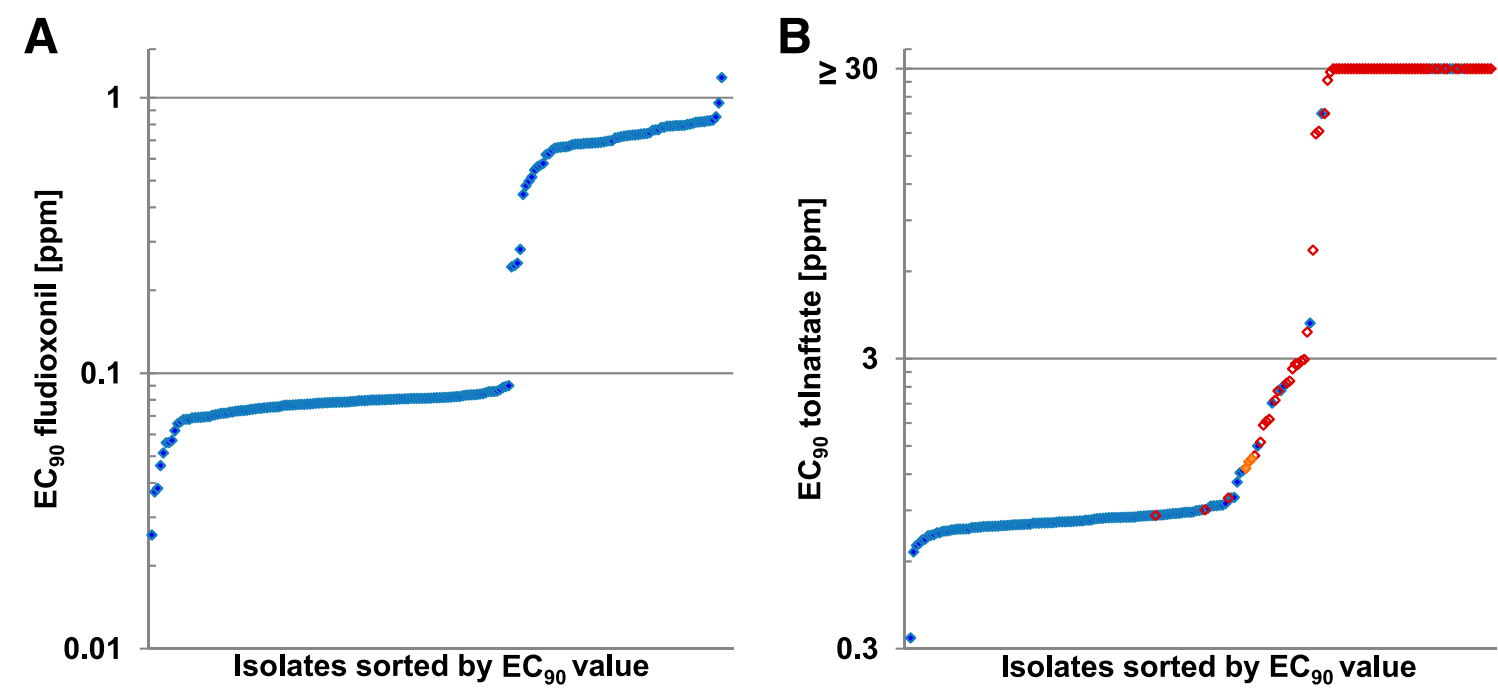

Fig. 2. Sensitivities of Botrytis cinerea isolates toward fludioxonil and tolnaftate, as indication for multidrug resistance (MDR). Isolates are sorted by rising values for the concentration of a fungicide at which fungal development is inhibited by $90 \%\left(\mathrm{EC}_{90}\right)$ of $\mathbf{A}$, fludioxonil and $\mathbf{B}$, tolnaftate. Blue diamonds $(\bullet)=B$. cinerea field isolates, orange diamonds $=B$. cinerea MDR1 and MDR2 reference strain, and red diamonds $=B$. cinerea isolates with $E C_{90}$ values above $0.2 \mathrm{ppm}$ for fludioxonil. 
revealed increased $\mathrm{EC}_{90}$ values for tolnaftate, an indication of MDR. The only type of MDR that has previously been observed in $B$. cinerea isolates from strawberry is MDR 1 and its stronger variant, MDR1h $(32,33,37)$. MDR1and MDR1h mainly cause reduced sensitivities to AP and PP fungicides and, in fact, the MDR isolates in our study showed not only reduced fludioxonil but also reduced pyrimethanil sensitivities, which indicated that they were MDR1 or MDR1h. A previous study had shown that MDR1 did not significantly alter the sensitivity to boscalid and iprodione (32). Our MDR isolates, however, showed a shift of boscalid and iprodione sensitivities, which
A

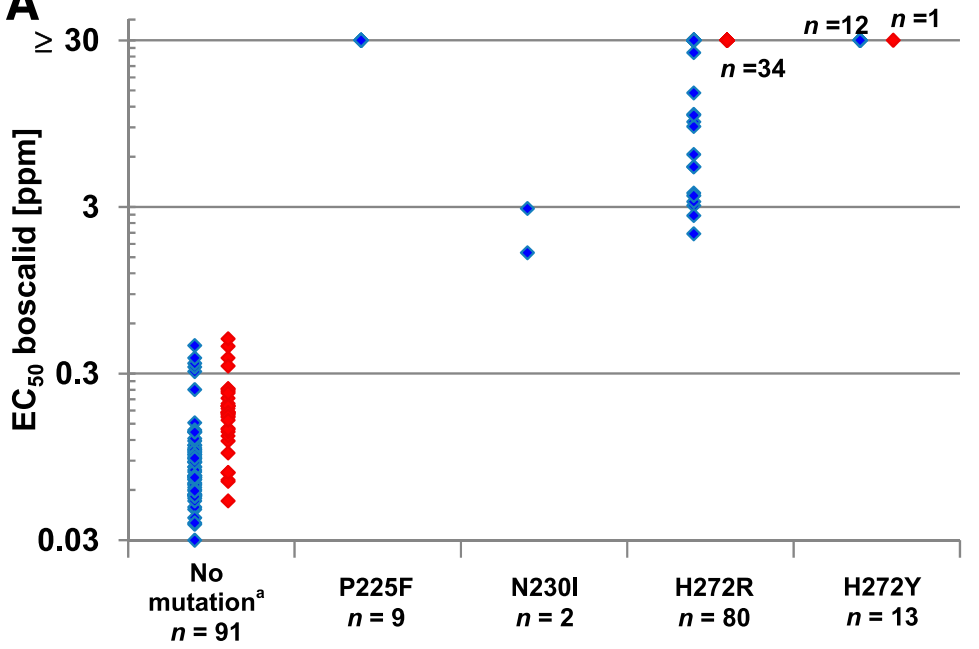

B

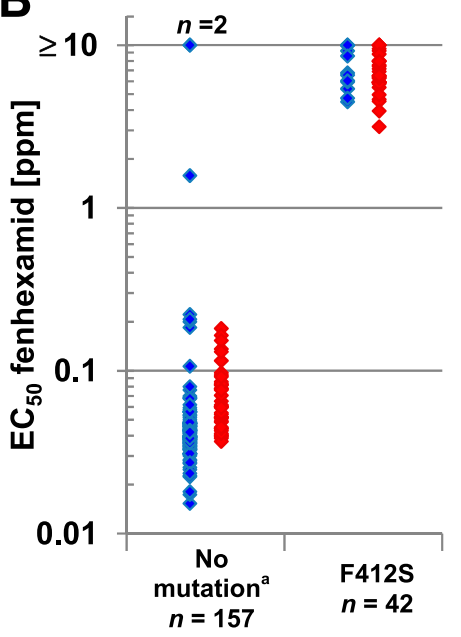

$c$

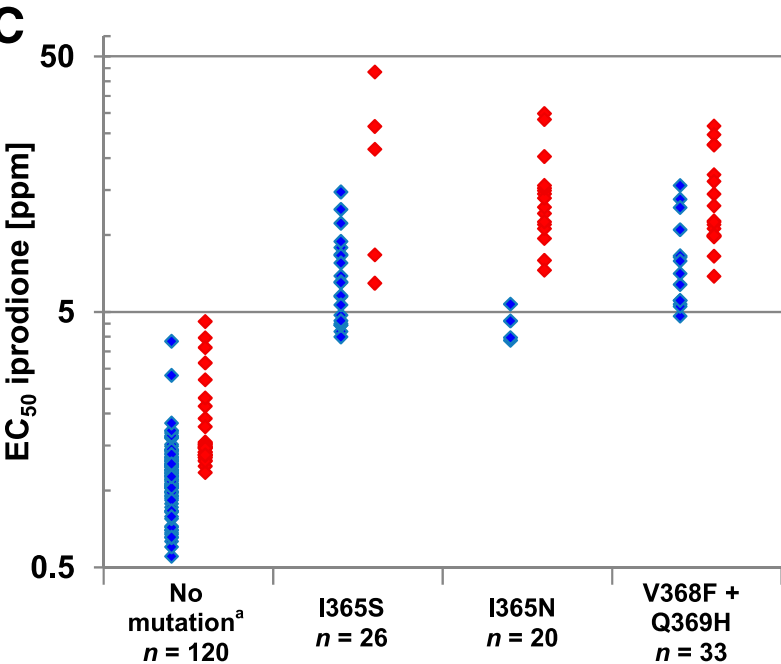

$\mathbf{E}$

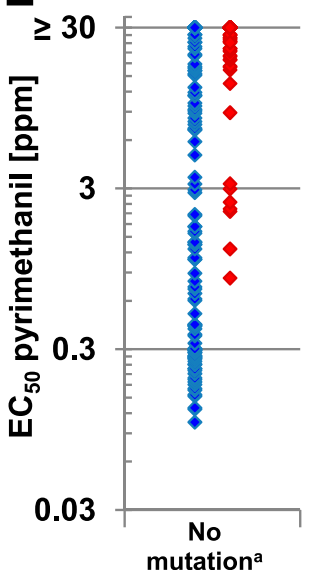

D

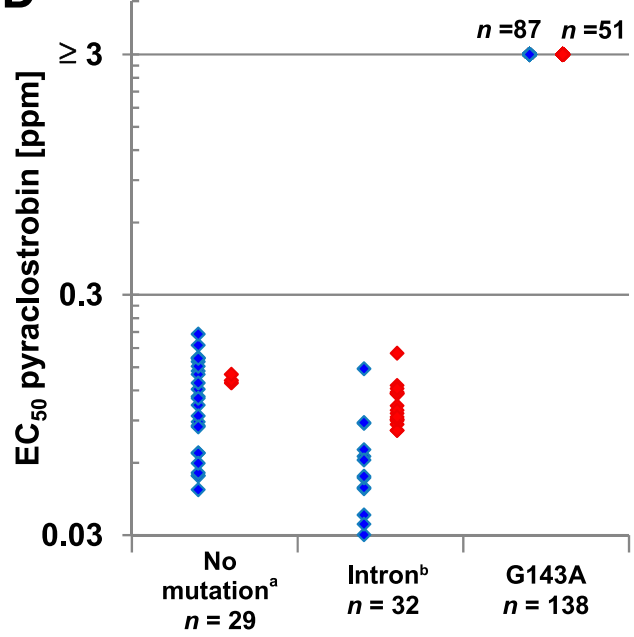

Fig. 3. Sensitivities of Botrytis cinerea isolates toward A, boscalid; B, fenhexamid; C, iprodione; D, pyraclostrobin; and E, pyrimethanil and the influence of corresponding resistance mechanisms on values for the concentration of a fungicide at which fungal development is inhibited by $50 \%\left(\mathrm{EC}_{50}\right)$. Blue diamonds $(\bullet)=B$. cinerea isolates with $\mathrm{EC}_{90}$ values below 0.1 and $1.13 \mathrm{ppm}$ for fludioxonil and tolnaftate, respectively; and red diamonds $=B$. cinerea isolates with $\mathrm{EC}_{90}$ values above 0.2 and 1.25 ppm for fludioxonil and tolnaftate, respectively (indication of multidrug resistance). a, No mutation detected in the target gene fragment analyzed by the pyrosequencing method used in this study (isolate with $\mathrm{EC}_{50}$ value of $1.58 \mathrm{ppm}$ for fenhexamid carried V234I and I235V mutation in erg27). b. Presence of the intron after G143. 
is an argument against the assumption that they may be MDR1 or MDR1h.

Eleven isolates in our study had high $\mathrm{EC}_{90}$ values for tolnaftate (higher than our MDR reference strains) but without a decrease in fludioxonil sensitivity. MDR2 previously found in $B$. cinerea isolates from vineyards mainly confers reduced sensitivity to APs, DCs, and HAs and only slightly lowers the sensitivity to fludioxonil and, therefore, could be an explanation for the low fludioxonil sensitivity levels of these tolnaftate-resistant isolates. MDR2 is based on a rearrangement of the $m f s M 2$ promotor region $(32,41)$. A PCR analysis of the $m f s M 2$ upstream region of those 11 tolnaftate-resistant isolates and 30 additional isolates, however, did not reveal the presence of such a rearrangement (data not shown). These results suggest that MDR2 may be absent in our $B$. cinerea collection, and raises the question of whether the tolnaftate-resistant and fludioxonil-sensitive isolates may be a yet unknown type of MDR.

Previous research shows that MDR caused by fungicide efflux provides $B$. cinerea with low levels of resistance toward several different MoA. Because resistance factors are considered to be low, and no loss in field performance caused by this mechanism has ever been reported, it appears that MDR isolates could easily be managed by applying the full doses of the fungicidal product (54). Our study, however, indicated that this may be only partially true. Whereas MDR by itself creates a slight shift toward lower sensitivity levels compared with the sensitive isolates, it may have a greater effect on sensitivity when combined with point mutations in the target site. This effect was particularly observed for isolates with amino acid change H272R in SdhB or I365S, I365N, or V368F + Q369H in Bos1. A previous study of $B$. cinerea field isolates from strawberry and blackberry also noted this phenomenon. Although low levels of iprodione resistance were associated with amino acid changes I365S or I365N, the four highly resistant isolates had a combination of I365S/N and increased drug efflux pump activity (23). This positive interaction of resistance mechanisms is commonly known from bacteria and the human pathogen $C$. albicans. For example, Pseudomonas aeruginosa strains that overexpressed the efflux pump MexAB-PprM or MexCD-OprJ and had mutations in the DNA gyrase were significantly more resistant to quinolones than those carrying only one of these resistance mechanisms $(8,39,42)$. In $C$. albicans strains from human immunodeficiency virus-infected patients, the combination of point mutations in the ERG11 gene with the upregulation of efflux pumps was responsible for high level fluconazole resistance (45).

The positive interaction of two resistance mechanisms in $B$. cinerea field isolates may potentially create isolates with high levels of resistance to several different classes of fungicides and, thus, is of great concern for resistance management. In our study, MDR was only detected using

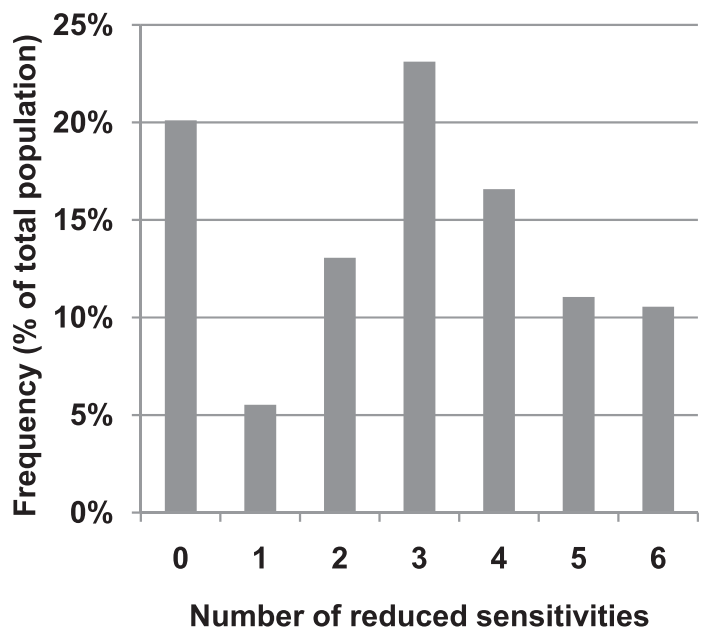

Fig. 4. Frequency of Botrytis cinerea isolates with various numbers of reduced sensitivities. The number of reduced sensitivities indicates the number of fungicides to which an individual isolate showed reduced sensitivities. phenotypic evidences, such as a decreased sensitivity to fludioxonil and tolnaftate. To determine and confirm which types of MDR are involved, further research is needed. This research should also focus on identifying how exactly this combination of resistance mechanisms functions, and should analyze the potential effect of this mechanism on fungicide efficacy in the field.

Thus far, reduced sensitivities of $B$. cinerea field isolates to fludioxonil were always based on increased drug efflux pump activities $(32,33,37)$; this was also true for the isolates in our collection. High levels of fludioxonil resistance have been detected only in laboratory mutants, and were linked to a decrease in fitness (16). This fitness penalty explains the absence of $B$. cinerea isolates with high levels of fludioxonil resistance in the field. Because the costs for point mutations which cause fludioxonil resistance appear to be too high for $B$. cinerea field isolates, MDR seems to be the sole mechanism selected by the application of fludioxonil. Thus, the distribution of MDR in $B$. cinerea field isolates appears to be driven by fludioxonil applications. Therefore, future studies should focus on the potential impact of PP applications on the development of resistance to fungicides with unrelated MoA.

However, the resistance situation of this trial site for the evaluation of fungicide efficacies against gray mold is surely not representative for most commercial sites because strawberry plants have been grown on this site for many years. A high selection pressure has been there over many years because of the intensive fungicide use under conditions which were maintained favorably for disease development. The samples had been taken after applications of the four fungicides that contained the different MoAs that were investigated in the study. There were still isolates with full sensitivity to all MoA and without an MDR phenotype. There were also isolates with reduced sensitivity to one or more, or even all, MoA.

The wild-type sequence of the target proteins is thought to represent the optimum which evolution "created" under conditions without fungicide selection pressure, and it could be speculated that any change (e.g., in the form of amino acid exchanges) may cause penalties for enzyme activity and, eventually, for the fungus. In fact, a lower fitness of isolates with a reduced sensitivity to DCs has been described in various studies $(18,19,30,43,46)$. These fitness costs are obviously also relevant for the field because the frequency of DC resistance decreased in time periods without selection pressure (29). Billard et al. (4) recently described that strains with F412 mutations in Erg27 have fitness penalties compared with isogenic wild-type strains. Reduced enzyme activity was also shown for SDH with different mutations in different organisms $(36,47)$, and a reduced fitness and less competitiveness in dual-inoculation tests were recently described by Veloukas et al. (53) for different SDH mutants of $B$. cinerea. The AP Working Group of the Fungicide Resistance Action Committee (FRAC) stated in recent years that the frequency of AP resistance is stable in Venturia inaequalis and B. cinerea, even if APs are still used for the control of these pathogens (http://www.frac.info). This might also indicate that AP-resistant isolates have a lower competitiveness than wild-type strains in time periods without selection pressure. In contrast to the other fungicides, QoI resistance conferred by the G143A mutation in CytB seems to have only low fitness costs because, for several pathogens, the majority of the populations have remained QoI resistant in various regions for many years (e.g., for Blumeria graminis f. sp. tritici or Zymoseptoria tritici; http://www.frac.info). Veloukas et al. (53) reported that the CytB G143A substitution did not show any fitness costs in Botrytis cinerea. However, a reduction of frequency of QoI resistance has been reported for Podosphaera fusca (26) and Plasmopara viticola when QoI selection pressure has been omitted or reduced $(20,51)$. If constitutive overexpression of efflux transporters in B. cinerea, as is the case for the MDR types, has any impact on their fitness, it has not yet been reported. It is likely that the summation of resistance mechanisms in one isolate leads to a summation of fitness penalties. Such isolates would have lower fitness than isolates with less or no resistance, especially during periods without selection pressure (e.g., after harvest or during winter). Therefore, follow-up studies will focus on the dynamic of the multiple resistances in $B$. cinerea over different seasons on the same site. 
The various resistance phenotypes indicate that there is a need to keep as many MoA as possible as tools for gray mold control. These should be used in spray programs to improve efficacy and resistance management. The use of different MoA in combination and alternation, and limitation of the number of application of a MoA, are important and effective resistance management strategies (25) to avoid or delay the occurrence and spread of (multiple) resistant isolates in populations. Application at the optimal time point is also critical for resistance management (52). Thus, applications of single-site inhibitors with anti-Botrytis activity should be avoided beyond the most important Botrytis infection time. Selection pressure should be reduced by nonchemical measurements such as crop cultural practices which are unfavorable for gray mold and phytosanitary measures (e.g., removal of infected fruit and plant material). Consideration should be given to restricting the use of MoA with a high risk for resistance development in farms for plant production and propagation to avoid generating and rapidly spreading resistant strains via plant material. Following the FRAC recommendations for the different MoA is a "must" and these can be viewed on the FRAC webpage (http:// www.frac.info).

\section{Acknowledgments}

We thank A. Hawlik and B. Wieja for excellent technical assistance and J. B. Speakman for critical reading of the manuscript. Parts of the studies were supported by funds of the Federal Ministry of Food and Agriculture (BMEL) based on a decision of the Parliament of the Federal Republic of Germany via the Federal Office for Agriculture and Food (BLE) under the innovation support program.

\section{Literature Cited}

1. Albertini, C., and Leroux, P. 2004. A Botrytis cinerea putative 3-keto reductase gene (ERG27) that is homologous to the mammalian $17 \beta$-hydroxysteroid dehydrogenase type 7 gene (17 $\beta$-HSD7). Eur. J. Plant Pathol. 110:723-733.

2. Alfonso, C., Raposo, R., and Melgarejo, P. 2000. Genetic diversity in Botrytis cinerea populations on vegetable crops in greenhouses in south - eastern Spain. Plant Pathol. 49:243-251.

3. Baraldi, E., Bertolini, P., Chierici, E., Trufelli, B., and Luiselli, D. 2002. Genetic diversity between Botrytis cinerea isolates from unstored and cold stored kiwi fruit. J. Phytopathol. 150:629-635.

4. Billard, A., Fillinger, S., Leroux, P., Lachaise, H., Beffa, R., and Debieu, D. 2012. Strong resistance to the fungicide fenhexamid entails a fitness cost in Botrytis cinerea, as shown by comparisons of isogenic strains. Pest Manag. Sci. 68:684-691.

5. Braun, P. G., and Sutton, J. C. 1987. Inoculum sources of Botrytis cinerea in fruit rot of strawberries in Ontario. Can. J. Plant Pathol. 9:1-5.

6. Bristow, P. R., McNicol, R. J., and Williamson, B. 1986. Infection of strawberry flowers by Botrytis cinerea and its relevance to grey mould development. Ann. Appl. Biol. 109:545-554.

7. Brooks, C., and Cooley, J. S. 1917. Temperature relations of apple-rot fungi. J. Agric. Res. 8:139-164.

8. Bruchmann, S., Dotsch, A., Nouri, B., Chaberny, I. F., and Haussler, S. 2013. Quantitative contributions of target alteration and decreased drug accumulation to Pseudomonas aeruginosa fluoroquinolone resistance. Antimicrob. Agents Chemother. 57:1361-1368.

9. Bulger, M. A., Ellis, M. A., and Madden, L. V. 1987. Influence of temperature and wetness duration on infection of strawberry flowers by Botrytis cinerea and disease incidence of fruit originating from infected flowers. Phytopathology 77:1225-1230.

10. Cui, W., Beever, R. E., Parkes, S. L., and Templeton, M. D. 2004. Evolution of an osmosensing histidine kinase in field strains of Botryotinia fuckeliana (Botrytis cinerea) in response to dicarboximide fungicide usage. Phytopathology 94:1129-1135.

11. De Miccolis Angelini, R. M., Pallastro, S., and Faretra, F. 2012. Genetics of fungicide resistance in Botryotinia fuckeliana (Botrytis cinerea). Pages 237-250 in: Fungicide Resistance in Crop Protection: Risk and Management. T. S. Thind, ed. CABI, Oxfordshire, UK.

12. Dianez, F., Santos, M., Blanco, R., and Tello, J. C. 2002. Fungicide resistance in Botrytis cinerea isolates from strawberry crops in Huelva (southwestern Spain). Phytoparasitica 30:529-534.

13. Fernández-Ortuño, D., Chen, F., and Schnabel, G. 2012. Resistance to pyraclostrobin and boscalid in Botrytis cinerea isolates from strawberry fields in the Carolinas. Plant Dis. 96:1198-1203.

14. Fernández-Ortuño, D., Chen, F., and Schnabel, G. 2013. Resistance to cyprodinil and lack of fludioxonil resistance in Botrytis cinerea isolates from strawberry in North and South Carolina. Plant Dis. 97:81-85.

15. Fernández-Ortuño, D., Grabke, A., Bryson, P. K., Amiri, A., Peres, N. A., and Schnabel, G. 2014. Fungicide resistance profiles in Botrytis cinerea from southern state strawberry fields. Plant Dis. 98:825-833.

16. Fillinger, S., Ajouz, S., Nicot, P. C., Leroux, P., and Bardin, M. 2012. Functional and structural comparison of pyrrolnitrin- and iprodione-induced modifications in the class III histidine-kinase Bos1 of Botrytis cinerea. PLoS One 7:e42520.

17. Fillinger, S., Leroux, P., Auclair, C., Barreau, C., Al Hajj, C., and Debieu, D. 2008. Genetic analysis of fenhexamid-resistant field isolates of the phytopathogenic fungus Botrytis cinerea. Antimicrob. Agents Chemother. 52:3933-3940.

18. Fourie, P. H., and Holz, G. 1998. Frequency of dicarboximide resistant strains of Botrytis cinerea in South African table grape vineyards and influence of spray schedules on resistant sub-populations. S. Afr. J. Enol. Vitic. 19:3-9.

19. Fraile, A., Alonso, A., and Sagasta, E. M. 1986. Some characteristics of Botrytis cinerea isolates tolerant to procymidone. Plant Pathol. 35:82-85

20. Genet, J. L., Jaworska, G., and Deparis, F. 2006. Effect of dose rate and mixtures of fungicides on selection for QoI resistance in populations of Plasmopara viticola. Pest Manag. Sci. 62:188-194.

21. Giraud, T., Fortini, D., Levis, C., Leroux, P., and Brygoo, Y. 1997. RFLP markers show genetic recombination in Botryotinia fuckeliana (Botrytis cinerea) and transposable elements reveal two sympatric species. Mol. Biol. Evol. 14 $1177-1185$.

22. Gisi, U., Sierotzki, H., Cook, A., and McCaffery, A. 2002. Mechanisms influencing the evolution of resistance to Qo inhibitor fungicides. Pest Manag. Sci. 58:859-867.

23. Grabke, A., Fernández-Ortuño, D., Amiri, A., Li, X., Peres, N. A., Smith, P., and Schnabel, G. 2014. Characterization of iprodione resistance in Botrytis cinerea from strawberry and blackberry. Phytopathology 104:396-402.

24. Grabke, A., Fernández-Ortuño, D., and Schnabel, G. 2013. Fenhexamid resistance in Botrytis cinerea from strawberry fields in the Carolinas is associated with four target gene mutations. Plant Dis. 97:271-276.

25. Hobbelen, P. H. F., Paveley, N. D., Oliver, R. P., and van den Bosch, F. 2013 The usefulness of fungicide mixtures and alternation for delaying the selection for resistance in populations of Mycosphaerella graminicola on winter wheat: A modeling analysis. Phytopathology 103:690-707.

26. Ishii, H., Yano, K., Date, H., Furuta, A., Sagehashi, Y., Yamaguchi, T., Sugiyama, T., Nishimura, K., and Hasama, W. 2007. Molecular characterization and diagnosis of QoI resistance in cucumber and eggplant fungal pathogens. Phytopathology 97:1458-1466.

27. Jarvis, W. R. 1962. The infection of strawberry and raspberry fruits by Botrytis cinerea. Fr. Ann. Appl. Biol. 50:569-575.

28. Jersch, S., Scherer, C., Huth, G., and Schlösser, E. 1989. Proanthocyanidins as basis for quiescence of Botrytis cinerea in immature strawberry fruits Z. Pflanzenkrankh. Pflanzenschutz 96:365-378.

29. Johnson, K. B., Sawyer, T. L., and Powelson, M. L. 1994. Frequency of benzimidazole- and dicarboximide-resistant strains of Botrytis cinerea in western Oregon small fruit and snap bean plantings. Plant Dis. 78:572-577.

30. Katan, T. 1982. Resistance to 3,5-dichlorophenyl-N-cyclic imide ('dicarboximide') fungicides in the grey mould pathogen Botrytis cinerea on protected crops. Plant Pathol. 31:133-141.

31. Kerssies, A., Bosker-van Zessen, A. I., Wagemakers, C. A. M., and van Kan, J. A. L. 1997. Variation in pathogenicity and DNA polymorphism among Botrytis cinerea isolates sampled inside and outside a glasshouse. Plant Dis. 81:781-786.

32. Kretschmer, M., Leroch, M., Mosbach, A., Walker, A.-S., Fillinger, S., Mernke, D., Schoonbeek, H., Pradier, J.-P., Leroux, P., and De Waard, M. A. 2009. Fungicide-driven evolution and molecular basis of multidrug resistance in field populations of the grey mould fungus Botrytis cinerea PLoS Pathog. 5:e1000696.

33. Leroch, M., Plesken, C., Weber, R. W. S., Kauff, F., Scalliet, G., and Hahn, M. 2013. Gray mold populations in German strawberry fields are resistant to multiple fungicides and dominated by a novel clade closely related to Botrytis cinerea. Appl. Environ. Microbiol. 79:159-167.

34. Leroux, P. 2004. Chemical control of Botrytis and its resistance to chemical fungicides. Pages 195-222 in: Botrytis: Biology, Pathology and Control. Y. Elad, B. Williamson, P. Tudzynski, and N. Delen, eds. Kluwer Academic Publishers, Dordrecht, The Netherlands.

35. Leroux, P., Gredt, M., Leroch, M., and Walker, A.-S. 2010. Exploring mechanisms of resistance to respiratory inhibitors in field strains of Botrytis cinerea, the causal agent of gray mold. Appl. Environ. Microbiol. 76: 6615-6630.

36. Li, J., Zhou, M., Li, H., Chen, C., Wang, J., and Zhang, Y. 2006. A study on the molecular mechanism of resistance to amicarthiazol in Xanthomonas campestris pv. citri. Pest Manag. Sci. 62:440-445.

37. Li, X., Fernández-Ortuño, D., Grabke, A., and Schnabel, G. 2014. Resistance to fludioxonil in Botrytis cinerea isolates from blackberry and strawberry. Phytopathology 104:724-732.

38. Li, X.-Z., and Nikaido, H. 2004. Efflux-mediated drug resistance in bacteria Drugs 64:159-204.

39. Lomovskaya, O., Lee, A., Hoshino, K., Ishida, H., Mistry, A., Warren, M. S. Boyer, E., Chamberland, S., and Lee, V. J. 1999. Use of a genetic approach to evaluate the consequences of inhibition of efflux pumps in Pseudomonas aeruginosa. Antimicrob. Agents Chemother. 43:1340-1346.

40. Ma, Z., Yan, L., Luo, Y., and Michailides, T. J. 2007. Sequence variation in the two-component histidine kinase gene of Botrytis cinerea associated with resistance to dicarboximide fungicides. Pestic. Biochem. Physiol. 88:300-306.

41. Mernke, D., Dahm, S., Walker, A.-S., Lalève, A., Fillinger, S., Leroch, M. and Hahn, M. 2011. Two promoter rearrangements in a drug efflux 
transporter gene are responsible for the appearance and spread of multidrug resistance phenotype MDR2 in Botrytis cinerea isolates in French and German vineyards. Phytopathology 101:1176-1183.

42. Nakajima, A., Sugimoto, Y., Yoneyama, H., and Nakae, T. 2002. High-level fluoroquinolone resistance in Pseudomonas aeruginosa due to interplay of the MexAB-OprM efflux pump and the DNA gyrase mutation. Microbiol. Immunol. 46:391-395.

43. Northover, J. 1983. Segregation and parasitic fitness of isolates of Botrytis cinerea resistant to iprodione. Can. J. Plant Pathol. 5:215-221.

44. Oshima, M., Fujimura, M., Banno, S., Hashimoto, C., Motoyama, T., Ichiishi, A., and Yamaguchi, I. 2002. A point mutation in the two-component histidine kinase $B c O S-1$ gene confers dicarboximide resistance in field isolates of Botrytis cinerea. Phytopathology 92:75-80.

45. Perea, S., Lopez-Ribot, J. L., Kirkpatrick, W. R., McAtee, R. K., Santillan, R. A., Martinez, M., Calabrese, D., Sanglard, D., and Patterson, T. F. 2001. Prevalence of molecular mechanisms of resistance to azole antifungal agents in Candida albicans strains displaying high-level fluconazole resistance isolated from human immunodeficiency virus-infected patients. Antimicrob. Agents Chemother. 45:2676-2684.

46. Raposo, R., Gomez, V., Urrutia, T., and Melgarejo, P. 2000. Fitness of Botrytis cinerea associated with dicarboximide resistance. Phytopathology 90 : 1246-1249.

47. Scalliet, G., Bowler, J., Luksch, T., Kirchhofer-Allan, L., Steinhauer, D., Ward, K., Niklaus, M., Verras, A., Csukai, M., and Daina, A. 2012. Mutagenesis and functional studies with succinate dehydrogenase inhibitors in the wheat pathogen Mycosphaerella graminicola. PLoS One 7:e35429.

48. Stammler, G., Brix, H. D., Nave, B., Gold, R., and Schoefl, U. 2008. Studies on the biological performance of boscalid and its mode of action. Pages 45-51 in: 15th Int. Reinhardsbrunn Symp. V. H. W. Dehne, H. B. Deising, U. Gisi, K. H. Kuck, P. E. Russell, and H. Lyr, eds. Friedrichroda, Germany.
49. Stammler, G., and Speakman, J. 2006. Microtiter method to test the sensitivity of Botrytis cinerea to boscalid. J. Phytopathol. 154:508-510.

50. Sutton, J. C. 1998. Botrytis fruit rot (gray mold) and blossom blight. Pages 28-31 in: Compendium of Strawberry Diseases, 2nd ed. J. L. Maas, ed. American Phytopathological Society, St. Paul, MN.

51. Toffolati, S. L., Prandato, M., Serrati, L., Sierotzki, H., Gisi, U., and Vercesi, A. 2008. Monitoring QoI resistance in Plasmopara viticola oospore populations. Pages 159-165 in: Modern Fungicides and Antifungal Compounds. V. H. W. Dehne, U. Gisi, K. H. Kuck, P. E. Russell, and H. Lyr, eds. Spectrum Phytomedizin, Braunschweig, Germany.

52. van den Berg, F., van den Bosch, F., and Paveley, N. D. 2013. Optimal fungicide application timings for disease control are also an effective antiresistance strategy: A case study for Zymoseptoria tritici (Mycosphaerella graminicola) on wheat. Phytopathology 103:1209-1219.

53. Veloukas, T., Kalogeropoulou, P., Markoglou, A., and Karaoglanidis, G. 2014. Fitness and competitive ability of Botrytis cinerea field-isolates with dual resistance to SDHI and QoI fungicides, associated with several $s d h \mathrm{~B}$ and the cytb G143A mutations. Phytopathology 104:347-356.

54. Walker, A.-S., Micoud, A., Rémuson, F., Grosman, J., Gredt, M., and Leroux, P. 2013. French vineyards provide information that opens ways for effective resistance management of Botrytis cinerea (grey mould). Pest Manag. Sci. 69:667-678

55. Weber, R. W. S. 2011. Resistance of Botrytis cinerea to multiple fungicides in Northern German small-fruit production. Plant Dis. 95:1263-1269.

56. Weber, R. W. S., and Hahn, M. 2011. A rapid and simple method for determining fungicide resistance in Botrytis. J. Plant Dis. Prot. 118:17-25.

57. Wilcox, W. F., and Seem, R. C. 1994. Relationship between strawberry gray mold incidence, environmental variables, and fungicide applications during different periods of the fruiting season. Phytopathology 84:264-270.

58. Williamson, B., Tudzynski, B., Tudzynski, P., and van Kan, J. A. L. 2007 Botrytis cinerea: The cause of grey mould disease. Mol. Plant Pathol. 8:561-580. 